\title{
Relation of optic disc topography and age to thickness of retinal nerve fibre layer as measured using scanning laser polarimetry, in normal subjects
}

\author{
Ahmet Baris Toprak, Ömer Faruk Yilmaz
}

\begin{abstract}
Aims-To evaluate the relation of the optic nerve head topographic measurements and age with the thickness of the retinal nerve fibre layer (RNFL) in normal Caucasoid subjects by means of scanning laser polarimetry and tomography.

Methods-Topographic optic disc measurements and RNFL thickness values of 38 normal Caucasoid subjects of both sexes aged 20 to 78 were measured using a confocal scanning laser ophthalmoscope and a confocal scanning laser polarimeter. One eye was randomly selected for statistical analysis. The effects of optic disc size, age, and optic disc head topographic measurements of total and regional RNFL thickness were evaluated.
\end{abstract}

Results-Age showed a significant correlation with the integral of the total RNFL thickness $(R=-0.341, p<0.05)$. The optic disc size showed a significant correlation with the integral of the total, superior, and inferior quadrant RNFL thickness $(R=0.425, \quad p<0.01), \quad(R=0.361, \quad p<0.05)$, $(R=0.468, p<0.05)$. Neuroretinal rim area (NRA) had a correlation with the superior and inferior quadrant RNFL thickness values $\quad(R=0.339, \quad p<0.05) \quad(R=0.393$, $\mathrm{p}<0.05)$. There was no significant correlation between the other optic disc topographic measurements and RNFL thickness values $(p>0.05)$.

Conclusion-The thickness of total as well as superior and inferior quadrant peripapillary RNFL as measured by scanning laser polarimetry increased significantly with an increase in optic disc size. The cross sectional area occupied by superior and inferior polar RNFL increased significantly with an increase in NRA. The total cross sectional area occupied by RNFL decreased significantly with an increase in age. The effects of optic disc size, age, and NRA should be considered when the peripapillary RNFL thickness is evaluated. (Br f Ophthalmol 2000;84:473-478)

The objective and quantitative measurement of peripapillary retinal nerve fibre layer (RNFL) is now considered possible with a recently developed technique, scanning laser polarimetry, which relies on the assumption that the parallel arrangement of microtubules within the RNFL causes a change in the state of polarisation of an illuminating laser beam, also known as retardation. ${ }^{1-6}$ The amount of retardation of the incident laser light is proportional to the thickness of the tissue through which it has passed. Thickness measurements of RNFL as expressed in $\mu \mathrm{m}$ are based on studies of cynomolgus monkey eyes with anterior segments removed, in which 1 degree of retardation corresponded to $7.4 \mu \mathrm{m}$ of thickness. ${ }^{5}$ Supposedly, the same correlation applies to human eyes, although this has not been validated. Several studies have obtained good reproducibility with the first version of the instrument. ${ }^{16}$ However, the reproducibility of measurements was very operator dependent. ${ }^{7}$ The later version of the instrument (NFA II) has a noticeably improved reproducibility of measurements both within and between observers. ${ }^{8} 9$ Likewise, it is now possible to have reliable sophisticated three dimensional analysis of the optic nerve head with the development of confocal scanning laser tomography. ${ }^{10-13}$

Some variables of RNFL retardation values can differentiate patients with glaucoma or ocular hypertension from normal subjects. ${ }^{14} 15$ However, considerable variability in RNFL thickness values among normal subjects, and some overlap in thickness values between normal subjects and glaucoma patients has been reported in several studies conducted by scanning laser polarimetry. ${ }^{16}{ }^{14-17}$ For the time being, the usefulness of scanning laser polarimetry for glaucoma screening in the general population and the predictability of glaucoma in patients with abnormal variable values and normal visual fields have not yet been determined. ${ }^{14}$ Tjon-Fo-Sang and Lemij reported that scanning laser polarimetry had a sensitivity of $96 \%$ and a specificity of $93 \% .^{2}$ However, the high sensitivity and specificity reported by Tjon-Fo-Sang and Lemij could not be reproduced in other studies. ${ }^{14} 18$

The number of nerve fibres and the configuration of the optic nerve head vary considerably in the normal population; the size of the scleral canal, the tilt of the optic nerve head, and the number of the nerve fibres and their arrangement all contribute to this variation. ${ }^{19-22}$ Previous histological studies of humans and other primates have shown a correlation between optic disc size, retrobulbar nerve fibre count, and neuroretinal rim area (NRA), with a linear increase in optic nerve count and NRA with an increase in optic disc size. ${ }^{23-26}$ Similar correlations of optic disc size with optic nerve head topographic measurements have been 
Table 1 Integral of retinal nerve fibre layer (RNFL) thickness in 38 normal eyes

\begin{tabular}{ll}
\hline Integral of the thickness of the RNFL $\left(\mathrm{mm}^{2}\right)$ & Mean (SD) \\
\hline Total & $0.548(0.097)$ \\
Superior quadrant & $0.172(0.043)$ \\
Temporal quadrant & $0.098(0.028)$ \\
Inferior quadrant & $0.165(0.035)$ \\
Nasal quadrant & $0.115(0.022)$
\end{tabular}

Superior quadrant $v$ inferior quadrant $p>0.05$; superior quadrant $v$ nasal quadrant $\mathrm{p}>0.05$; superior quadrant $v$ temporal quadrant $\mathrm{p}<0.05$; inferior quadrant $v$ nasal quadrant $\mathrm{p}>0.05$; inferior quadrant $v$ temporal quadrant $\mathrm{p}<0.05$; temporal quadrant $v$ nasal quadrant $\mathrm{p}<0.05$ (ANOVA and Scheffé's test).

Table 2 Values of optic disc variables in 38 normal subjects

\begin{tabular}{lr}
\hline Variable (unit) & \multicolumn{1}{c}{ Mean $(S D)$} \\
\hline Optic disc size $\left(\mathrm{mm}^{2}\right)$ & $2.325(0.441)$ \\
Contour modulation $(\mathrm{mm})$ & $0.144(0.041)$ \\
Contour variation $(\mathrm{mm})$ & $0.424(0.750)$ \\
Mean contour depth $(\mathrm{mm})$ & $0.066(0.145)$ \\
Effective area $\left(\mathrm{mm}^{2}\right)$ & $0.834(0.546)$ \\
$1 / 2$ depth area $\left(\mathrm{mm}^{2}\right)$ & $0.245(0.176)$ \\
$1 / 2$ depth volume $\left(\mathrm{mm}^{3}\right)$ & $-0.035(0.038)$ \\
NRA $\left(\mathrm{mm}^{2}\right)$ & $1.490(0.470)$ \\
Volume above $\left(\mathrm{mm}^{3}\right)$ & $0.326(0.174)$ \\
Volume below $\left(\mathrm{mm}^{3}\right)$ & $-0.198(0.185)$ \\
C/D ratio $†$ & $0.348(0.195)$ \\
Average depth $\left(\mathrm{mm}^{3}\right)$ & $-0.205(0.103)$ \\
Maximum depth $(\mathrm{mm})$ & $-0.537(0.222)$ \\
\hline
\end{tabular}

${ }^{\star} \mathrm{NRA}=$ neuroretinal $\mathrm{rim}$ area $; \mathrm{C} / \mathrm{D}=$ cup/disc;

shown to occur by scanning laser tomography. ${ }^{27}$ A previous study conducted by scanning laser polarimetry has demonstrated that the peripapillary RNFL thickness increases linearly as the area of the optic nerve head increases. ${ }^{28}$ Thus, it seems reasonable to examine the relation of RNFL thickness and other optic nerve head variables in order to be able to predict with more precision what the individualised normal RNFL thickness for a specific individual with known ocular variables is and to explain some part of this high variability.

In addition, age affects the number of optic nerve fibres of an individual. A loss of optic nerve axons with age in the human optic nerve has been reported. ${ }^{29-31}$ In this study we investigated the effect of age on RNFL thickness as measured by scanning laser polarimetry. We have also examined the relations between RNFL thickness and different optic nerve head topographic measurements in normal subjects measured by means of scanning laser polarim-

Table 3 Correlations between optic disc variables and age $(x)$ and total integral of RNFL thickness (y) in 38 normal subjects

\begin{tabular}{|c|c|c|c|c|}
\hline Variable & Equation & $p$ Value & $R^{*}$ & $R^{2} \dagger$ \\
\hline Age & $y=-0.002 x+0.641$ & 0.036 & -0.341 & 0.117 \\
\hline Disc area & $y=0.093 x+0.330$ & 0.008 & 0.425 & 0.181 \\
\hline Average depth & $\mathrm{y}=-0.167 \mathrm{x}+0.529$ & 0.407 & -0.215 & 0.046 \\
\hline $\mathrm{C} / \mathrm{D} \ddagger$ ratio & $y=-0.029 x+0.558$ & 0.728 & -0.058 & 0.003 \\
\hline Contour modulation & $\mathrm{y}=0.566 \mathrm{x}+0.482$ & 0.260 & 0.289 & 0.084 \\
\hline Contour variation & $y=0.276 x+0.447$ & 0.321 & 0.256 & 0.066 \\
\hline $1 / 2$ depth area & $\mathrm{y}=0.134 \mathrm{x}+0.531$ & 0.252 & 0.294 & 0.086 \\
\hline $1 / 2$ depth volume & $\mathrm{y}=-0.129 \mathrm{x}+0.559$ & 0.815 & -0.062 & 0.004 \\
\hline Effective area & $y=0.018 x+0.533$ & 0.546 & 0.101 & 0.010 \\
\hline Maximum depth & $\mathrm{y}=0.010 \mathrm{x}+0.553$ & 0.893 & 0.023 & 0.001 \\
\hline Mean contour depth & $y=0.035 x+0.546$ & 0.753 & 0.053 & 0.003 \\
\hline NRAS & $y=0.058 x+0.461$ & 0.084 & 0.284 & 0.081 \\
\hline Volume above & $y=0.067 x+0.526$ & 0.473 & 0.120 & 0.014 \\
\hline Volume below & $y=-0.059 x+0.536$ & 0.504 & -0.112 & 0.013 \\
\hline
\end{tabular}

${ }^{\star} \mathrm{R}=$ correlation coefficient; $\nmid \mathrm{R}^{2}=$ determination coefficient; $\ddagger \mathrm{C} / \mathrm{D}=\mathrm{cup} / \mathrm{disc}, \S \mathrm{NRA}=$ neuroretinal rim area. etry and tomography. We aimed to specify some of the factors that will enable clinicians to define better age specific and optic disc size specific normal ranges for RNFL thickness which may improve the specificity of the instrument.

\section{Subject and methods}

Thirty eight Caucasoid normal adults of both sexes were enrolled into this study. The study population consisted of volunteers from the staff of the World Eye Hospital and patients with minor refractive disorders. Informed consent was obtained from each subject. The inclusion criteria were: best corrected visual acuity of 20/25; intraocular pressure less than $21 \mathrm{~mm} \mathrm{Hg}$ as measured by Goldmann applanation tonometry; no significant ocular disease found in routine eye examination; normal appearance of optic nerve head with a 90 dioptre lens on slit lamp microscopy; a refractive error of less than plus or minus 4 dioptres of sphere and plus or minus 2 dioptres of cylinder; no history of glaucoma in the family. All measurements were done by the same examiner who has 1 year of experience. All measurements were made in a dimly lit room. Pupillary dilatation was not used.

The basic principles and technical characteristics of the scanning laser polarimeter (Nerve Fibre Analyser II, Laser Diagnostic Technologies, version 2.1.15 Alpha, San Diego, CA, USA) have been described extensively. ${ }^{42}$ In brief, the device is a scanning laser ophthalmoscope with integrated instrumentation for measuring polarisation. The light source consists of a $780 \mathrm{~nm}$ diode laser in which the state of polarisation is modulated. The polarised light penetrates the birefringent RNFL and is partially reflected from the deeper layers of retina. The light emerging from the eye is separated from the illuminating light beam by a non-polarising beam splitter. Consequently the polarisation state of the light is analysed by the polarisation detection unit. A compensation device was used to neutralise the birefringent properties of the anterior segment of the eye. The electrical signal from the detector is digitised and stored in the memory of a personal computer.

A total of 65536 retinal locations $(256 \times$ 256 pixels) were tested to create a retardation map in which the thickness of RNFL was measured for each location. Three images per eye in a single session were obtained and were averaged. In the present study a 15 degree field size was used and the optic disc was centred in the centre of image. The thickness of the RNFL was measured within a band 10 pixels wide that was located concentrically with the optic disc margin at 1.75 disc diameters.

The margin of the optic disc was approximated by a circle placed around the inner margin of the peripapillary scleral ring. The integral of the thickness of RNFL was determined within the entire peripapillary circular band and for 90 degree quadrants (superior, temporal, inferior, and nasal).

The basic operational principles of confocal scanning laser tomography have been de- 


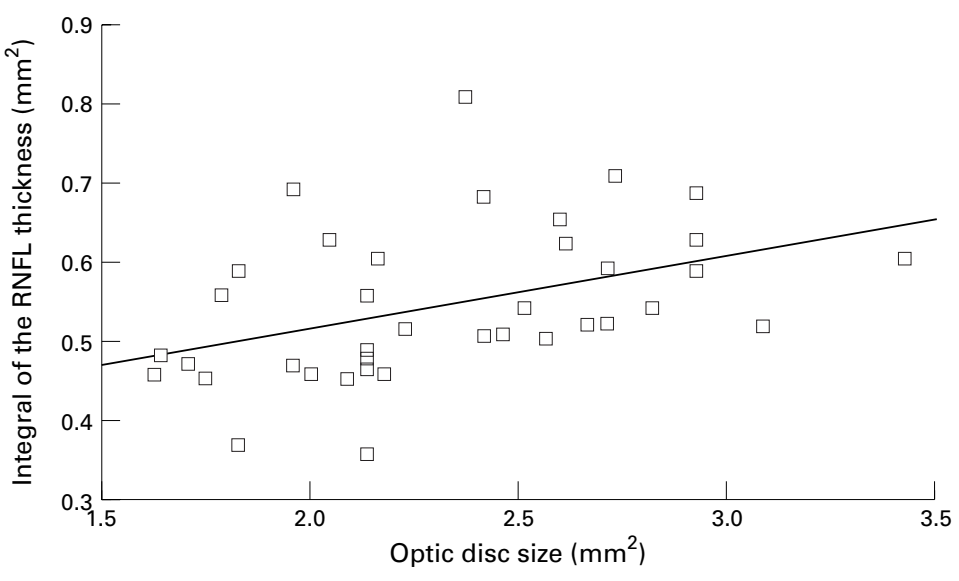

Figure 1 Correlation between the optic disc size and the integral of the total RNFL thickness in 38 normal eyes $\left(Y=0.093 x+0.330, p<0.01, R=0.425, R^{2}=0.181\right)$.

Table 4 Correlations between optic disc variables and age $(x)$ and superior quadrant integral of RNFL thickness (y) in 38 normal subjects

\begin{tabular}{lllrl}
\hline Variable & Equation & $p$ Value & \multicolumn{1}{c}{$R^{\star}$} & $R^{2} t$ \\
\hline Age & $\mathrm{y}=-7.3 \mathrm{E}-04 \mathrm{x}+0.206$ & 0.088 & -0.280 & 0.079 \\
Disc area & $\mathrm{y}=0.035 \mathrm{x}+0.091$ & 0.026 & 0.361 & 0.130 \\
Average depth & $\mathrm{y}=-0.135 \mathrm{x}+0.147$ & 0.129 & -0.384 & 0.147 \\
C/D ratio $\neq$ & $\mathrm{y}=-0.030 \mathrm{x}+0.182$ & 0.412 & -0.137 & 0.019 \\
Contour modulation & $\mathrm{y}=0.196 \mathrm{x}+0.146$ & 0.395 & 0.221 & 0.049 \\
Contour variation & $\mathrm{y}=-0.003 \mathrm{x}+0.176$ & 0.981 & -0.006 & 0.000 \\
1/2 depth area & $\mathrm{y}=0.095 \mathrm{x}+0.151$ & 0.064 & 0.459 & 0.211 \\
1/2 depth volume & $\mathrm{y}=-0.197 \mathrm{x}+0.167$ & 0.427 & -0.206 & 0.043 \\
Effective area & $\mathrm{y}=9.2 \mathrm{E}-04 \mathrm{x}+0.172$ & 0.993 & -0.001 & 0.000 \\
Maximum depth & $\mathrm{y}=0.032 \mathrm{x}+0.189$ & 0.320 & 0.166 & 0.028 \\
Mean contour depth & $\mathrm{y}=0.035 \mathrm{x}+0.170$ & 0.482 & 0.118 & 0.014 \\
NRA & $\mathrm{y}=0.031 \mathrm{x}+0.126$ & 0.037 & 0.339 & 0.115 \\
Volume above & $\mathrm{y}=0.049 \mathrm{x}+0.156$ & 0.228 & 0.200 & 0.040 \\
Volume below & $\mathrm{y}=-0.005 \mathrm{x}+0.171$ & 0.901 & -0.021 & 0.000 \\
\hline
\end{tabular}

${ }^{\star} \mathrm{R}=$ correlation coefficient; $\nmid \mathrm{R}^{2}=$ determination coefficient; $\ddagger \mathrm{C} / \mathrm{D}=\mathrm{cup} / \mathrm{disc} ; \Omega N R A=$ neuroretinal rim area.

scribed before. ${ }^{33}$ Optic disc topographic measurements were acquired and analysed using a confocal scanning ophthalmoscope (TopSS, Laser Diagnostic Technologies, version 2.2.16, San Diego, CA, USA), which operates with a near infrared diode laser $(790 \mathrm{~nm})$. It has a confocal aperture of $30 \mu \mathrm{m}$ in diameter, which is approximately $24 \mu \mathrm{m}$ on the retina. Light returning from the posterior segment passes through this small confocal aperture and is detected. Light from any other point out of focus is detected minimally or attenuated greatly.

Scanning laser tomography was performed in a $10 \times 10$ degree field to obtain maximum possible resolution. For image acquisition, an

Table 5 Correlations between optic disc variables and age $(x)$ and inferior quadrant integral of RNFL thickness (y) in 38 normal subjects

\begin{tabular}{llrrr}
\hline Variable & Equation & $p$ Value & \multicolumn{1}{c}{$R^{\star}$} & $R^{2} \dagger$ \\
\hline Age & $\mathrm{y}=-6.23 \mathrm{E}-04 \mathrm{x}+0.194$ & 0.076 & -0.291 & 0.085 \\
Disc area & $\mathrm{y}=0.037 \mathrm{x}+0.078$ & 0.003 & 0.468 & 0.219 \\
Average depth & $\mathrm{y}=-0.017 \mathrm{x}+0.169$ & 0.829 & -0.057 & 0.003 \\
C/D ratio $\neq$ & $\mathrm{y}=-0.024 \mathrm{x}+0.173$ & 0.420 & -0.135 & 0.018 \\
Contour modulation & $\mathrm{y}=0.181 \mathrm{x}+0.146$ & 0.367 & 0.234 & 0.055 \\
Contour variation & $\mathrm{y}=0.099 \mathrm{x}+0.130$ & 0.369 & 0.233 & 0.054 \\
1/2 depth area & $\mathrm{y}=0.031 \mathrm{x}+0.165$ & 0.505 & 0.174 & 0.030 \\
$1 / 2$ depth volume & $\mathrm{y}=0.013 \mathrm{x}+0.173$ & 0.954 & 0.015 & 0.000 \\
Effective area & $\mathrm{y}=0.003 \mathrm{x}+0.162$ & 0.816 & 0.039 & 0.002 \\
Maximum depth & $\mathrm{y}=0.009 \mathrm{x}+0.169$ & 0.734 & 0.057 & 0.003 \\
Mean contour depth & $\mathrm{y}=0.033 \mathrm{x}+0.162$ & 0.422 & 0.134 & 0.018 \\
NRA & $\mathrm{y}=0.029 \mathrm{x}+0.121$ & 0.015 & 0.393 & 0.154 \\
Volume above & $\mathrm{y}=0.056 \mathrm{x}+0.146$ & 0.090 & 0.279 & 0.078 \\
Volume below & $\mathrm{y}=-0.012 \mathrm{x}+0.162$ & 0.717 & -0.061 & 0.004 \\
\hline
\end{tabular}

${ }^{\star} \mathrm{R}=$ correlation coefficient; $+\mathrm{R}^{2}=$ determination coefficient; $\ddagger \mathrm{C} / \mathrm{D}=\mathrm{cup} / \mathrm{disc} ; \Omega \mathrm{NRA}=$ neuroretinal rim area. active focusing unit generates 32 confocal images within a predetermined depth. Each image is digitised at $256 \times 256$ pixels. Processing of the image series generates a summary image called a topographic image. Three image series per eye in a single session were obtained, and the three depth values obtained were averaged. By determining the margin of the optic disc in the same manner as the NFA image, optic disc topographic measurements were automatically calculated. They are: mean contour depth, the average of all the height values along the defined margin of the optic disc; effective area, the area of the optic cup; neuroretinal rim area, the difference between the total disc area and the effective area; cup/disc ratio, calculated by dividing the effective area by the total disc area; volume above, the volume of all tissue or structure within the neuroretinal rim area; volume below, the volume of the cup below the effective area; maximum depth, average of the lowest $5 \%$ of all the height values; contour variation, the difference between the maximum height and the minimum height values along the defined margin of the optic disc; contour modulation, the maximum height minus the minimum height along the circle, divided by the maximum height plus the minimum height along the ellipse; $1 / 2$ depth area, the area of all points half way between the cup margin and the bottom, $1 / 2$ depth volume, the volume of the cup below the $1 / 2$ depth area.

One eye of each individual selected randomly by tossing a coin was chosen for statistical analysis. Data are reported as mean and standard deviation (SD). Linear regression analysis was used to calculate correlation coefficients. Statistical comparisons of groups utilised analysis of variance (ANOVA) followed by multiple comparison test (Scheffé's test). A level of $p<0.05$ was considered statistically significant.

\section{Results}

The mean age of the subjects was 46.2 (SD 15.6) (range $20-78$ years). There were $50 \%$ $(n=19)$ males and $50 \%(n=19)$ females. The mean spherical refractive error was $0.67(0.77)$ and the mean astigmatic error was $0.51(0.38)$. Table 1 shows means and standard deviations of the optic disc size and the integral of the RNFL thickness in the total peripapillary circular band and its four 90 degree quadrants. The integral of the RNFL thickness was greatest in the superior and inferior quadrants, and smallest in the temporal quadrant. The integral of the RNFL at the temporal quadrant was significantly smaller than the other three quadrant values $(\mathrm{p}<0.05)$ (Table 1$)$. The mean optic disc size was $2.325(0.441) \mathrm{mm}^{2}$ and ranged from $1.624 \mathrm{~mm}^{2}$ to $3.424 \mathrm{~mm}^{2}$. Table 2 shows means and standard deviations of other optic disc topographic measurements.

There was a significant correlation between optic disc size and the total of the integral of the RNFL thickness for the entire peripapillary circular band $(p<0.01)$ (Table 3$)$. Figure 1 shows this relation as a scatter plot. There was also a significant correlation between optic disc 


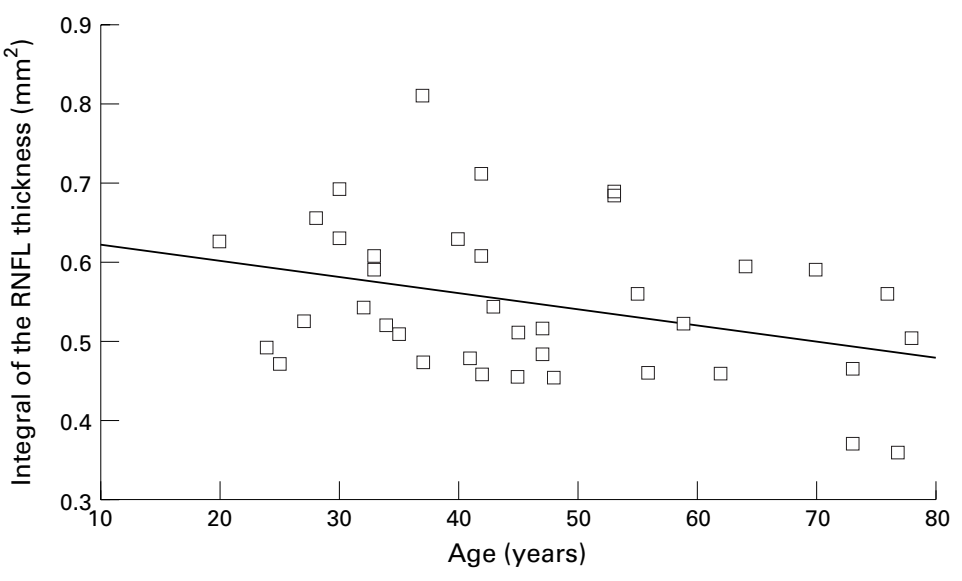

Figure 2 Correlation between age and the integral of the total RNFL thickness of the $R N F L$ in 38 normal eyes $\left(Y=-0.002 x+0.641, p<0.05, R=-0.341, R^{2}=0.117\right)$.

size and the integral of the thickness of the RNFL for the superior and inferior quadrants $(\mathrm{p}<0.05)$ (Tables 4 and 5).

There was a decrease in the total integral of the RNFL thickness as age grew, which was statistically significant $(p<0.05)$ (Table 3). Figure 2 shows this relation as a scatter plot.

There was a significant correlation between NRA and superior quadrant of the integral of the RNFL thickness (Table 4). There was also a significant correlation between NRA and inferior quadrant of the integral of the RNFL thickness (Table 5). There was not a significant relation between the integral of the RNFL thickness values and the remainder of the optic

Table 6 Correlations between optic disc variables and age $(x)$ and nasal quadrant integral of RNFL thickness (y) in 38 normal subjects

\begin{tabular}{lllrl}
\hline Variable & Equation & $p$ Value & \multicolumn{1}{c}{$R^{\star}$} & $R^{2} t$ \\
\hline Age & $\mathrm{y}=-3.4 \mathrm{E}-04 \mathrm{x}+0.131$ & 0.125 & -0.253 & 0.064 \\
Disc area & $\mathrm{y}=0.013 \mathrm{x}+0.084$ & 0.105 & 0.267 & 0.071 \\
Average depth & $\mathrm{y}=-0.017 \mathrm{x}+0.112$ & 0.715 & -0.096 & 0.009 \\
C/D ratio $\neq$ & $\mathrm{y}=-0.009 \mathrm{x}+0.118$ & 0.651 & -0.076 & 0.006 \\
Contour modulation & $\mathrm{y}=0.054 \mathrm{x}+0.108$ & 0.645 & 0.121 & 0.015 \\
Contour variation & $\mathrm{y}=0.054 \mathrm{x}+0.093$ & 0.397 & 0.220 & 0.048 \\
1/2 depth area & $\mathrm{y}=0.003 \mathrm{x}+0.115$ & 0.912 & 0.029 & 0.001 \\
1/2 depth volume & $\mathrm{y}=0.056 \mathrm{x}+0.118$ & 0.655 & 0.117 & 0.014 \\
Effective area & $\mathrm{y}=0.001 \mathrm{x}+0.114$ & 0.898 & 0.022 & 0.000 \\
Maximum depth & $\mathrm{y}=-0.002 \mathrm{x}+0.114$ & 0.911 & -0.019 & 0.000 \\
Mean contour depth & $\mathrm{y}=0.003 \mathrm{x}+0.115$ & 0.883 & 0.247 & 0.001 \\
NRAS & $\mathrm{y}=0.011 \mathrm{x}+0.098$ & 0.158 & 0.234 & 0.055 \\
Volume above & $\mathrm{y}=-0.001 \mathrm{x}+0.116$ & 0.950 & -0.010 & 0.000 \\
Volume below & $\mathrm{y}=-0.002 \mathrm{x}+0.115$ & 0.928 & -0.015 & 0.000 \\
\hline
\end{tabular}

${ }^{\star} \mathrm{R}=$ correlation coefficient; $\nmid \mathrm{R}^{2}=$ determination coefficient; $¥ \mathrm{C} / \mathrm{D}=\mathrm{cup} / \mathrm{disc} ; \mathbb{N R A}=$ neuroretinal rim area.

Table 7 Correlations between optic disc variables and age $(x)$ and temporal quadrant integral of RNFL thickness (y) in 38 normal subjects.

\begin{tabular}{|c|c|c|c|c|}
\hline Variable & Equation & $p$ Value & $R^{*}$ & $R^{2} \dagger$ \\
\hline Age & $\mathrm{y}=2.8 \mathrm{E}-04 \mathrm{x}+0.111$ & 0.332 & -0.162 & 0.026 \\
\hline Disc area & $\mathrm{y}=0.011 \mathrm{x}+0.072$ & 0.303 & 0.172 & 0.029 \\
\hline Average depth & $y=0.005 x+0.102$ & 0.952 & 0.016 & 0.000 \\
\hline $\mathrm{C} / \mathrm{D}$ ratio $\ddagger$ & $\mathrm{y}=0.031 \mathrm{x}+0.087$ & 0.204 & 0.211 & 0.044 \\
\hline Contour modulation & $y=0.113 x+0.085$ & 0.547 & 0.157 & 0.025 \\
\hline Contour variation & $\mathrm{y}=0.116 \mathrm{x}+0.052$ & 0.253 & 0.293 & 0.086 \\
\hline $1 / 2$ depth area & $y=0.003 x+0.101$ & 0.948 & 0.017 & 0.000 \\
\hline $1 / 2$ depth volume & $\mathrm{y}=-0.002 \mathrm{x}+0.101$ & 0.994 & -0.002 & 0.000 \\
\hline Effective area & $\mathrm{y}=0.014 \mathrm{x}+0.086$ & 0.103 & 0.269 & 0.072 \\
\hline Maximum depth & $\mathrm{y}=-0.024 \mathrm{x}+0.085$ & 0.256 & -0.189 & 0.036 \\
\hline Mean contour depth & $\mathrm{y}=-0.033 \mathrm{x}+0.099$ & 0.314 & -0.168 & 0.028 \\
\hline NRAS & $y=-0.009 x+0.111$ & 0.382 & -0.146 & 0.021 \\
\hline Volume above & $y=-0.034 x+0.109$ & 0.209 & -0.209 & 0.043 \\
\hline Volume below & $\mathrm{y}=-0.035 \mathrm{x}+0.091$ & 0.165 & -0.230 & 0.053 \\
\hline
\end{tabular}

${ }^{\star} \mathrm{R}=$ correlation coefficient; $\nmid \mathrm{R}^{2}=$ determination coefficient; $\ddagger \mathrm{C} / \mathrm{D}=\mathrm{cup} / \mathrm{disc} ; \S \mathrm{NRA}=$ neuroretinal rim area. disc topographic measurements obtained via TopSS (Tables 6 and 7).

\section{Discussion}

In the present study, we have investigated the correlation between variables such as age and various optic nerve head topographic measurements, and the integrals of the RNFL thickness of the four quadrants separately and with the integral of the RNFL thickness in the total peripapillary circular band. We have shown a positive correlation between the optic disc area and the total of the integral of the RNFL thickness. The thickness of the RNFL increased as the optic nerve head became bigger. The same kind of positive correlation also applied for the integral of the RNFL thickness for the superior and inferior quadrants. However, there was no correlation between the optic disc size and the integral of the RNFL thickness in the nasal and temporal quadrants.

The RNFL comprises ganglion cell axons, neuroglia, and astrocytes. Assuming that the composition of the monkey eye RNFL is similar to that of the human eye approximately $70 \%-82 \%$ of the tissue in the RNFL would be composed of neural/axonal tissue. ${ }^{34}{ }^{35}$ So it can be inferred that when the thickness of the peripapillary RNFL is measured by any means the amount of the peripapillary neural tissue is being measured to a great extent. The axonal part of the retrobulbar optic nerve is the extension of the axons of the retinal ganglion cells converging at the optic nerve head to form the optic nerve. Although some controversy exists, it has been shown that larger discs have a greater number of myelinated nerve fibres at the retrobulbar optic nerve as shown by histological studies of human and other primate eyes. $^{23} 243031$ The results of this study are in accordance with those of the histological studies which indicate a positive correlation between the optic disc size and the number of retrobulbar optic nerve fibres; there is a linear correlation between the thickness of the peripapillary RNFL and the number of the nerve fibres at the retrobulbar optic nerve.

Funaki et al have shown a positive correlation between the optic disc size and the integral of the peripapillary RNFL thickness in a study conducted by confocal scanning laser polarimetry. ${ }^{28}$ All of the four quadrants observed revealed the same kind of correlation between the optic disc size and the integral of the RNFL thickness. Our study population did not show any correlation between the optic disc size and the integral of the RNFL thickness for the temporal and nasal quadrants. However, there was a positive correlation between optic disc size and RNFL thickness at the superior and inferior quadrants. The retinal nerve fibre layer is thickest at the superior and inferior quadrants as shown by histomorphic and scanning laser ophthalmoscope studies. ${ }^{14-1736}{ }^{37}$ Although the inferior and superior quadrant RNFL thicknesses were found to be greater than the temporal and nasal quadrant RNFL thicknesses, only the difference between the temporal quadrant and 
the other three quadrants had reached significance in the present study. These results concur with those of the histological study by Varma et al. ${ }^{38}$

Funaki et al determined optic disc size by calculating the area of the ellipse placed around the inner margin of the peripapillary scleral ring on the NFA II image of the optic disc; this ellipse determining optic disc margin is used as a reference line to measure RNFL thickness within a band concentrically with the optic disc. ${ }^{28}$ In contrast with Funaki et al, we have correlated RNFL thickness measurements with optic disc topographic variables obtained via TopSS. The optic nerve head measurements such as the $\mathrm{C}: \mathrm{D}$ ratio, depth volume, area of the cup, NRA, the depth of the cup as measured by scanning laser tomography did not have a significant effect on the integral of the total RNFL thickness. However, there was a correlation between the NRA and integral of the RNFL thickness for the superior and inferior quadrants. The RNFL thickness and the NRA have been shown to increase as the optic disc size increased. ${ }^{25-28}$ Some experimental models of glaucoma have shown a correlation between the optic nerve head topographic variables measured by scanning laser tomography, such as the neuroretinal rim area and the number of optic nerve fibres. ${ }^{39}{ }^{40}$ The results of this study support the concept that the cross sectional area of the optic nerve fibres forming the neuroretinal rim is reflected as the thickness of the peripapillary nerve fibre layer and the thickness of the peripapillary RNFL is determined by the size of the optic disc. Any of the other optic nerve head measurements did not have a significant effect on the regional RNFL thickness values in the current study.

Magnification factors affect only the lateral measurements in NFA whereas TopSS is affected both laterally and axially. We have not used any magnification correction factor during data acquisition for this study. However, we believe that this has not affected our results as all the subjects included in the study had negligible ametropic refractive errors; 95\% $(n=36)$ of the subjects had less than 2.0 dioptres of spherical equivalent of ametropia.

Dichtl et al showed that in normal eyes with disc cupping, the difference between measurements with scanning laser polarimetry (Heidelberg Retina Tomograph, Heidelberg Engineering, Heidelberg, Germany) and planimetric methods were negatively correlated with the size of the optic cup and area of the optic disc. ${ }^{41}$ TopSS has been found to measure optic disc size with a normalisation factor of 1.26 with a Zeiss fundus camera. ${ }^{42}$ To our knowledge there is no study comparing TopSS measurements with planimetric methods considering the effects of variables such as disc and cup size and the presence of glaucoma. Planimetric methods are not free from error; however, they are the gold standard for studies of optic disc characteristics. The clinical significance of the findings of the current study should be validated using planimetric methods because of potential inaccuracy of the TopSS measurements of the optic disc and the relatively weak statistical power of the study as a p level of less than 0.05 was considered significant.

There is a considerable variation in RNFL thickness values among normal individuals as measured by scanning laser polarimetry. ${ }^{16}{ }^{14-17}$ Some of the histological studies have also revealed a large variation in the number of nerve fibres at the optic nerve in normal population. ${ }^{19}{ }^{20}$ In the present study a similar wide variation in the integral of RNFL thickness among normal individuals was also observed. However, the interaction of these findings needs to be clarified by further studies as there is no histological validation of what scanning laser polarimetry actually measures in humans. The study population of this study consisted of younger individuals than individuals with glaucoma. Further studies are necessary to see whether the same kind of findings apply to older individuals.

Although some controversy exists, ${ }^{19}{ }^{43}$ it was earlier reported in several histological studies using automated techniques of analysis of specimens, that there is a decline in the optic nerve fibre count with increasing age, with a rate of loss of 4000-5000 fibres per year. ${ }^{2429-31}$ Studies using scanning laser polarimeter have also demonstrated a progressive thinning of the RNFL with age. ${ }^{161516}$ These results concur with histological postmortem studies in human optic nerves. ${ }^{29}{ }^{31}$ We were not able to find any significant correlation between age and each of the four quadrants. However, we have observed a decline in the integral of the total RNFL thickness value with age, which is significant. The thickness of the RNFL decreased by $-7.6 \%$ per 10 years. Recently Choplin et al observed a significant decline in RNFL thickness with advancing age which was reported to be clinically insignificant. ${ }^{14}$ In contrast with the studies mentioned above, the progressive thinning of RNFL with age could not be demonstrated in a previous study conducted by scanning laser polarimeter. ${ }^{28}$

In summary, using scanning laser polarimetry and tomography, this study showed that the size of the optic disc significantly correlated with the total, superior, and inferior quadrant integral of the RNFL. A correlation between age and the RNFL thickness has been also observed, the total integral of the RNFL decreased significantly with age. The area of the neuroretinal rim as measured with scanning laser tomography correlated significantly with the superior and inferior quadrant integral of the RNFL thickness. Thus, when the RNFL thickness is evaluated, it should be remembered that the size of the optic disc, age, and the area of the neuroretinal rim influences the RNFL thickness values especially at the superior and inferior quadrants where the RNFL is thicker. It may be of some help to take these factors into consideration to define a narrower range of normal RNFL thickness for certain individuals in order to differentiate those with glaucomatous damage from normal subjects with more precision. 
The data presented here were gathered in 1997 with the approval of the ethics committee of the World Eye Hospital, Istanbul, when both authors worked as full time ophthalmologists.

1 Chi QM, Tomita G, Inazumi K, et al. Evaluation of the effect of ageing on the retinal nerve fibre layer thickness using scanning laser polarimetry. F Glaucoma 1995;4:406-13.

2 Tjon-Fo-Sang MJ, Lemij HG. The sensitivity and specificity of nerve fibre layer measurements in glaucoma as
determined with scanning laser polarimetry. Am f Ophthalmol 1997;123:62-9.

3 Weinreb RN, Shakiba S, Sample PA, et al. Association between quantitative nerve fibre layer measurement and visual field loss in glaucoma. Am $\mathcal{F}$ Ophthalmol 1995;120 732-8.

4 Dreher AW, Reiter K. Retinal laser ellipsometry; a new method of measuring the retinal nerve fibre layer thickness distribution? Clin Vis Sci 1992;7:481-8.

5 Weinreb RN, Dreher QW, Coleman A, et al. Histopathologic validation of Fourier-ellipsometry measurements of retinal nerve fibre layer thickness. Arch Ophthalmol 1990;108:557nerve

6 Weinreb RN, Shakiba S, Zangwill L. Scanning laser polarimetry to measure the retinal nerve fibre layer of normal and glaucomatous eyes. Am f Ophthalmol 1995;119. 627-36.

7 Lemij HG, Tjon-Fo-Sang M. The nerve fiber analyzer. In: Stamper RL, Schuman JS, eds. Ophthalmology Clinics of North America. Philadelphia: WB Saunders, 1998;11:41120.

8 Hoh ST, Ishikawa H, Greenfield DS, et al. Peripapillary nerve fiber layer thickness measurement reproducibility using scanning laser polarimetry. F Glaucoma 1998;7:1215.

9 Zangwill L, Berry CA, Garden VS, et al. Reproducibility of retardation measurements with the nerve fiber analyzer II. f Glaucoma 1997;6:384-9.

10 Chauhan BC, LeBlanc RP, McCormick TA, et al. Test-retest variability of topographic measurements with confocal scanning laser tomography in patients with glaucoma and control subjects. Am $\mathcal{f}$ Ophthalmol 1994;118:9-15.

11 Kruse FE, Burk ROW, Völcker H-E, et al. Reproducibility of topographic measurements of the optic nerve head with topographic measurements of the optic nerve head with
laser tomographic scanning. Ophthalmology 1989;96:13204 .

12 Beausnecourt E, Elsner AE, Hartnett ME, et al. Quantitative analysis of macular holes with scanning laser tomography. Ophthalmology 1997;104:2018-29.

13 Dreher AW, Tso PC, Weinreb RN. Reproducibility of topographic measurements of the normal and glaucomatous optic nerve head with the laser tomographic scanner. $A m f^{f}$ Ophthalmol 1991;111:221-9.

14 Choplin NT, Lundy DC, Dreher AW. Differentiating patients with glaucoma from glaucoma suspects and normal subjects by nerve fibre layer assessment with scanning laser polarimetry. Ophthalmology 1998:105;2068-81.

15 Tjon-Fo-Sang MJ, de Vries J, Lemij HG. Measurement by nerve fibre analyser of retinal nerve fibre layer thickness in normal subjects and patients with ocular hypertension. $A m$ f Ophthalmol 1996;122:220-7.

16 Poinoosawmy D, Fontana L, Wu JX, et al. Variation of nerve fibre layer thickness measurements with age and ethnicity by scanning laser polarimetry. Br f Ophthalmol 1997;81: by scannir.

17 Niessen AGJE, van den Berg TJTP, Langerhost CT, et al. Retinal nerve fibre layer assessment by scanning laser polarimetry and standardised photography. Am $\mathcal{F}$ Ophthalmol 1996;121:484-93.

18 Weinreb RN, Zangwill L, Berry CC, et al. Detection of glaucoma with scanning laser polarimetry. Arch Ophthalmol 1998;116:1583-9

19 Repka MX, Quigley HA. The effect of age on normal human optic nerve fiber number and diameter. Ophthalmology $1989 ; 96: 26-32$
20 Quigley HA, Brown AE, Morrison JD, et al. The size and shape of the optic disc in normal human eyes. Arch Ophthalmol 1990;108:51-7.

21 Jonas JB, Gusek GC, Naumann GOH. Optic disc, cup and neuroretinal rim size, configuration and correlation in normal eyes. Invest Ophthalmol Vis Sci 1988;29:1151-8.

22 Varma R, Tielsch JM, Quigley HA, et al. Race-, age, gender-, and refractive error-related differences in the normal optic disc. Arch Ophthalmol 1994;122:1068-76.

23 Quigley HA, Coleman AL, Dorman-Pease ME. Larger optic nerve heads have more nerve fibres in normal monkey eyes. Arch Ophthalmol 1991;109:1441-3.

24 Jonas JB, Schmidt AM, Müller-Bergh JA, et al. Human optic nerve count and optic disc size. Invest Ophthalmol Vis Sci 1992;33:2012-8.

25 Caprioli J, Miller JM. Optic disc rim area s related to disc size in normal subjects. Arch Ophthalmol 1987;105:1683-5.

26 Britton RF, Drance SM, Schulzer M, et al. The area of the neuroretinal rim of the optic nerve in normal eyes. Am $\mathcal{f}$ Ophthalmol 1987;103:497-504.

27 Kee C, Koo H, Ji Y, et al. Effect of optic disc size or age on evaluation of optic disc variables. Br f Ophthalmol 1997;81: $1046-9$

28 Funaki S, Shirakashi M, Abe H. Relation between size of optic disc and thickness of retinal nerve fibre layer in normal subjects. Br f Ophthalmol 1998;82:1242-5.

29 Balaszi AG, Rootman J, Drance SM. Ageing and the optic nerve. Am f Ophthalmol 1984;97:760-6.

30 Mikelberg FS, Yidegiligne HM, White VA, et al. Relation between optic nerve axon number and axon diameter to scleral canal area. Ophthalmology 1991;98:60-3.

31 Jonas JB, Muller-Berg JA, Schlotzer-Schrehardt UM, et al. Histomorphometry of the human optic nerve. Invest Ophthalmol Vis Sci 1990;31:736-44.

32 Dreher AW, Reiter K, Wienreg R. Spatially resolved birefringence of retinal nerve fiber layer assessed with retinal laser ellipsometer. Appl Optics 1992;31:3730-5.

33 Zinser G, Wijnaendts-va-Reandt RW, Dreher AW, et al. Confocal laser tomographic scanning of the eye. New Methods in Microscopy and Low Light Imaging 1989;1161: $337-44$

34 Ogden TE. Nerve fibre layer of the primate retina: thickness and glial content. Vis Res 1983;23:581-7.

35 Minckler DS, McLean IW, Tso MOM. Distribution of axonal and glial elements in the rhesus optic nerve head studied by electron microscopy. Am f Ophthalmol 1976;82: $179-87$.

36 Anton A, Zangwill L, Emdadi A, et al. Nerve fibre layer measurements with scanning laser polarimetry in ocular hypertension. Arch Ophthalmol 1997;115:331-4.

37 Radius RL. Thickness of the retinal nerve fibre layer in primate eyes. Arch Ophthalmol 1980;98:1625-9.

38 Varma R, Skaf M, Barron E. Retinal nerve fibre layer thickness in normal human eyes. Ophthalmology 1996;103: 2114-9

39 Yücel YH, Gupta NG, Kalichman MW, et al. Relationship of optic disc topography to optic nerve fibre in glaucoma. Arch Ophthalmol 1998:116:493-7.

40 Varma R, Quigley HA, Pease ME. Changes in optic disc characteristics and the number of nerve fibres in experimental glaucoma. Am F Ophthalmol 1992;114:554-9.

41 Dichtl A, Jonas JB, Mardin CY. Comparison between tomographic scanning evaluation and photographic measurement of the neuroretinal rim. Am f Ophthalmol 1996;121: 494-501.

42 Meyer TM, Howland SC. How large is the optic disc? Systematic errors in fundus cameras and topographers. Proc ARVO Annual Meeting (abstract) 1999;40:204-B164

43 Mikelberg FS, Drance SM, Schulzer M, et al. The normal human optic nerve. Ophthalmology 1989;96:1325-8. 